\title{
Up to date of prostate cancer
}

\author{
Özüm Atasoy'iD, Oytun Erbaş² ${ }^{\mathbb{D}}$ \\ ${ }^{1}$ Department of Radiation Oncology, Kartal Dr. Lütfi Kırdar Training and Research Hospital, Istanbul, Turkey \\ ${ }^{2}$ Department of Physiology, Istanbul Bilim University Faculty of Medicine, Istanbul, Turkey
}

\begin{abstract}
Prostate cancer is the most common cancer among men and is the second most common cause of cancer-related death in men following lung cancer. It is generally slow growing. The main risk factor is elderly age. Prognosis is generally good, but may vary depending on its pathologic subtype. Adenocarcinoma, which accounts for over $95 \%$ of cases, responds especially well when treated as localized disease. The main methods of treatment include radical prostatectomy, radiotherapy, and active surveillance, as well as chemotherapy, androgen deprivation treatment, and Radium-223.

Keywords: Androgen deprivation therapy, chemotherapy, prostate cancer, radiotherapy.
\end{abstract}

\section{EPIDEMIOLOGY}

Prostate cancer is the most commonly diagnosed cancer in men and second leading cause of cancer-related death in men following lung cancer. ${ }^{[1]}$ Mean age of diagnosis is 72 years of age, while only $1 \%$ of patients who are diagnosed are below the age of 50 . Worldwide cumulative risk of prostate cancer varies between 5-20\% at age $85 .^{[2,3]}$ However, according to the results of autopsy studies, while prostate cancer was identified in $60-70 \%$ of males over the age of 85 , only $10 \%$ of men develop clinical prostate cancer throughout their lifetime. ${ }^{[3]}$

The prevalence of prostate cancer has not changed over the past 30 years. ${ }^{[4]}$ Prostatespecific antigen (PSA) was first used to followup patients diagnosed with prostate cancer in 1987 and seven years later The Food and Drug Administration (FDA) approved its use as a screening test for prostate cancer. ${ }^{[5]}$ For this reason, available data shows that incidence rates of prostate cancer increased especially in the 1990s and later stabilized. Additionally, it is also thought that increased lifespan due to decrease in cardiovascular deaths may be associated with cancer incidence. ${ }^{[6]}$

Prostate cancer incidence greatly varies between different ethnic populations and countries and disease rates have been shown to vary between populations by as much as 90 times. The lowest rates are observed in Asia, especially in China and Tianjin (1-9 in 100,000 annually), while the highest rates are seen in North America and Scandinavia, especially in African Americans in the USA. ${ }^{[2]}$

\section{ETIOLOGY}

Age is the largest independent risk factor for prostate cancer. Cumulative cancerogenic exposure is thought to cause deoxyribonucleic acid (DNA) damage and oxidative stress.

The contribution of hereditary factors to the causality of sporadic cancer is uncertain. Studies on twins make it possible to predict the overall contribution of hereditary genes to the

Received: February 03, 2020 Accepted: April 22, 2020 Published online: August 25, 2020

Correspondence: Özüm Atasoy, MD. Kartal Dr. Lütfi Kırdar Eğitim Araştırma Hastanesi Radyasyon Onkolojisi Kliniği, 34890 Kartal, İstanbul, Türkiye. Tel: +90505 - 9560340 e-mail: ozumatasoy@gmail.com 
development of malignant diseases. Therefore, 44,788 pairs of twins in Sweden, Denmark, and Finland were followed up to evaluate the effect of genetics. It was observed that the twins of affected individuals had increased risk of stomach, colorectal, lung, breast, and prostate cancer. Among these cancers, it was found that prostate cancer is the cancer in which hereditary factors are most significant, and that genetic factors accounted for $42 \%$ of prostate cancer risk. ${ }^{[8]}$

Carter et al. ${ }^{[9]}$ found that the number of affected family members both increased the risk of cancer but was also associated with earlyonset cancer, in comparison to sporadic forms. In hereditary forms, the most common mutation is of the tumor suppressor RNASEL - Ribonuclease L (2',5'-oligoisoadenylate synthetase-dependent). ${ }^{[10]}$ Other than this, mutations in androgen receptors, ${ }^{[11]}$ vitamin D, CYP17 (17 $\alpha$-hydroxylase), ${ }^{[12]}$ SRD5A2 (5 $\alpha$-reductase, ${ }^{[13]}$ ELAC/HPC2, ${ }^{[14]}$ and MSR1 have also been identified.

Studies have shown that prostate cancer is associated with Western lifestyle, and especially high-fat diet rich in meat and dairy products. ${ }^{[15]}$ It was found that males who consumed at least $600 \mathrm{mg}$ Ca daily from dairy products had increased risk of developing prostate cancer compared to those with only consumed $150 \mathrm{mg}$ Ca daily and that it was associated with increased risk and metastatic disease. ${ }^{[16]}$

It was shown that $\alpha$-methyl-CoA racemase (AMACR) gene was overexpressed in prostate cancer tumors but not in the healthy prostate ${ }^{[17]}$ AMACR plays a role in the peroxisomal B oxidation of branched-chain fatty acids, which mainly originate from beef and dairy products, and also produce hydrogen peroxide, a potential carcinogen. This may explain why prostate cancer is more prevalent among countries with Western eating habits. In addition, another reason for the low incidence of prostate cancer in Asia may be the high consumption of dietary phytoestrogens. ${ }^{[18]}$

The Selenium and Vitamin E Cancer Prevention Trial (SELECT) studied the effects of vitamin $\mathrm{E}$, selenium, and their combinations on 32,400 participants. Vitamin $\mathrm{E}$ was found to be associated with 1.17 increased risk of prostate cancer. Neither selenium nor the combination was found to have significant results. ${ }^{[19]}$ In the Physicians' Health study, 14,641 male doctors were randomized for vitamin $\mathrm{E}$ and $\mathrm{C}$ supplements, which did not yield significant decrease in any cancer risk. ${ }^{[20]}$ In addition, lycopene was found to reduce the incidence of prostate cancer (Table 1). ${ }^{[21]}$

Medical castration lowers levels of testosterone, forming the basis of prostate cancer treatment. Therefore, high androgen exposure is believed to cause prostate cancer. In 1941, Huggins was awarded the Nobel Prize for his research on the role of androgen in prostate cancer. ${ }^{[22]}$

\section{SCREENING}

Blood PSA levels are most frequently used in screening. Prostate-specific antigen is a singlechain glycoprotein structure weighing 33-kd, which contains a sequence of 237 amino acids and sulfur bonds consisting of 4 carbohydrate side chains, and has chymotrypsin-like properties. Prostatespecific antigen is homologous with proteases in the kallikrein family and is also referred to as human glandular kallikrein 3 (hK-3). Prostatespecific antigen is a neutral serine protease that liquefies the seminal coagulum by hydrolyzing the seminal vesicle proteins semenogelin I and II. While only a small amount of PSA is free (f PSA), the majority is bound to $\alpha 2$ macroglobulin (AMG) and $\alpha-1$ antichymotrypsin (ACT). ${ }^{[23]}$

Half-life of PSA varies between 2.2 and 3.2 days and is expected to drop to the lowest levels after radical prostatectomy or hormone therapy treatment.

Serum PSA levels are directly related to age. Considering the age of prostate cancer diagnosis,

Table 1. Potential risk factors for prostate cancer ${ }^{[7]}$

Advanced age
Benign prostatic hyperplasia
Diet (e.g., fat intake)
Familial history of prostate cancer
Histologic precursors (e.g., prostatic intraepithelial neoplasia)
Hormonal factors (e.g., serum testosterone)
Occupational exposure (e.g., cadmium)
Race or ethnicity (e.g., black)
Sexual behaviour (e.g., multıpl partners)
Sexually transmitted disease (e.g., herpes virus)
Tobacco use
Vasectomy


new biomarkers are required. Prostate Cancer Antigen 3 (PCA3) is a non-coding RNA and is expressed 66 times more times in prostate adenocarcinoma than healthy prostate tissue and benign prostatic hyperplasia $(\mathrm{BPH}){ }^{.24]}$ This is its main advantage over PSA, which also increases in $\mathrm{BPH}$. Furthermore the transmembrane protease serine 2:v-ets erythroblastosis virus E26 oncogene homolog (TMPRSS2:ERG) fusion in urine has $90 \%$ more specificity in diagnosing prostate cancer. ${ }^{[24]}$

It has been suggested that 1,410 men should be screened and 48 men treated to prevent a single death related to prostate cancer and that only men aged 55-69 would benefit from screening. ${ }^{[25]}$ The American Urology Society (AUS) recommends that screening should start at age 50. Screening is recommended after the age of 40 in patients with first-degree relatives with prostate cancer. ${ }^{[26]}$ Screening is not recommended in men over age 70 with life expectancy less than 10-15 years.

\section{THE PROSTATE GLAND}

\section{Prostate gland anatomy}

The prostate, which is the largest accessory gland of the male genital system, is a cone-shaped organ which surrounds the prostatic urethra in the bone pelvis cavity, with its base on top and apex on the bottom. ${ }^{[23]}$

The base of the prostate is in continuity with the bladder and its apex is in continuity with the membranous urethra. The prostate has anterior, posterior, and two inferolateral surfaces.

The anterior surface is narrow and convex and located $2 \mathrm{~cm}$ away from the symphysis pubis, while this gap contains a rich venous plexus (Santorini plexus) and loose connective tissue. Two puboprostatic ligaments fixate the anterior surface to the pubic bone, while its inferolateral surfaces neighbor the levator ani muscle. In between, there is a rich vein plexus (lateral plexus) wrapped with prostatic sheaths. The posterior surface is separated from the rectal ampulla by means of the prostatic capsule and Denonvillier fascia, while both vesicles are adjacent to both seminal vesicles and ampulla of the ductus deferens. ${ }^{[23,27,28]}$

\section{Prostate gland histology}

Prostate epithelium consists of three main histologic structures: secretory, basal and neuroendocrine cells. Secretory cells produce PSA, prostatic acid phosphatase (PAP), acidic mucin, and other secretory products. Basal cells form the cell layer surrounding the basement membrane around the glands. These cells have the highest proliferative activity among the prostate epithelium and are thought to be a reserve of stem cells. ${ }^{[29]}$ Neuroendocrine cells are fewest in number.

\section{DIAGNOSIS}

\section{Pathology}

Over $95 \%$ of prostate cancers are adenocarcinoma and about $4 \%$ are transitional cell cancer. The rest consist of neuroendocrine carcinoma (small cell carcinoma) and sarcomas.

Prostate intraepithelial neoplasia (PIN) is the precursor form, in which cellular proliferation increases in the prostate. It is characterized by disruption in the basal cell layer and increased size of cell nuclei. ${ }^{[31]}$ Nuclear enlargement is considered high or low grade according to degree of nuclear and nucleolar enlargement. The clinical significance of this distinction is that when high-grade PIN is detected in prostate needle biopsy, approximately 30\% of cases are at risk of prostate cancer. If high-grade PIN rate is more than $20 \%$, re-biopsy is recommended as soon as possible. ${ }^{[32]}$

Among cases of prostate cancer, 70\% develop from the peripheral zone, $15-20 \%$ the central zone, and 5-10\% the transitional zone. Therefore, ultrasound-guided transrectal biopsy is the gold standard in diagnosis. ${ }^{[8]}$ Most prostate cancers are multifocal and may be encountered in various zones as various grades.

Minimum criteria for pathologic diagnosis were established by Algaba et al. ${ }^{[30]}$ The main criteria include infiltrative glandular growth pattern, absence of basal cell layer, nucleomegaly and nucleolomegaly. Lack of basal cells may be confirmed, if necessary, by high molecular weight cytokeratins (labeled with antibody $34 \beta E 12)$ or immunohistochemical staining for p63. Minor criteria include intraluminal blue mucin, pink amorphic secretions, mitotic figures, 
intraluminal crystalloids, adjacent high-grade PIN, and nuclear hyperchromasia. Another useful diagnostic marker that can be detected by immunohistochemistry is AMACR, an enzyme that is selectively expressed in the neoplastic glandular epithelium. The presence of antibodies directed against basal cells and AMACR is particularly useful in evaluating the foci of small atypical glands and confirming a minimal diagnosis of adenocarcinoma. ${ }^{[33]}$

The Gleason score used in grading was developed by the Veterans Administration study consisting of over 4,000 pathologies. Histologic differentiation is scored from 1 to 5 . Grade 1 is similar to normal pattern, while no glandular pattern is observed in grade 5. Grades of the most common primary patterns and secondary pattern are summed for a total value between 2 and 10 (Figure 1). ${ }^{[34]}$

\section{Clinical symptoms}

While most early stage patients are asymptomatic, presence of symptoms generally indicates local advanced stage or metastatic disease. Patients with prostate cancer most often present with prostatism, which is most common in $\mathrm{BPH}$, a syndrome characterized by difficulty urinating, intermittent urination, or

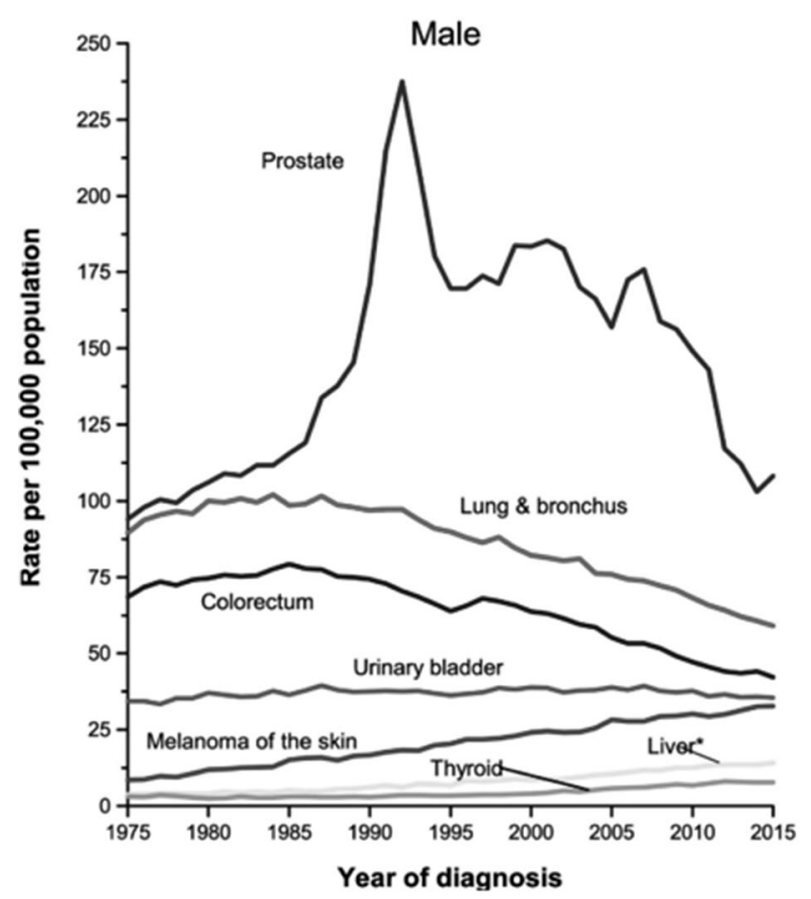

Figure 1. Cancer incidence in men according to years. ${ }^{[4]}$ frequent urination due to pressure on the ureter. Progression of the tumor towards the urethra or neck of the bladder or direct spread to the trigone leads to irritative and obstructive symptoms and hematuria. Uremic symptoms due to urethral obstruction, electrolyte imbalance, and hydronephrosis may occur. Hematospermia due to invasion of the seminal vesicle, edema in lower extremities as a result of lymphatic and venous obstruction in lymphatic metastasis, or erectile dysfunction due to cavernous nerve involvement may also develop. ${ }^{[23]}$ While the Denonvilliers' fascia is a barrier to rectal involvement, rarely, symptoms such as hematochezia and constipation may be seen. Impotence, perineal pain, and priapism may occur when neurovascular fibers, the urogenital diaphragm, or penile corporal body are involved. ${ }^{[8,23]}$

In metastatic disease, anorexia and weight loss due to systemic disease and increased cytokines, bone pains, pathological fractures, and vertebra metastases as a result of bone metastases, spinal cord compression and associated paresthesia or weakness in the lower limbs, and urinary or fecal incontinence may develop. ${ }^{[23]}$ Bone metastases occur, in order, in the vertebral column (74\%), costa (70\%), pelvis (60\%), femur (44\%) and shoulder girdle (41\%). ${ }^{[5]}$ However, one-third of patients are asymptomatic despite bone metastases. The frequency and pain of bone metastases are to related to the patient's response to treatment and surveillance. ${ }^{[36]}$ Studies have also indicated that PSA levels were correlated with the density of bone metastases in newly diagnosed patients. ${ }^{[37]}$

\section{Physical examination}

Complete physical examination is fundamental as it determines metastatic disease or other clinically significant circumstances. Digital rectal examination may be performed by the doctor in lithotomy-position, kneeling, lateral Sim's position, or in proctologic position. Hard and irregular prostate is typical, although cancer foci may also be found in a prostate with normal rectal examination. In these patients, cachexia, vesical globe due to infravesical obstruction, lymphedema due to lymphadenopathies in the lower extremities or deep vein thrombosis (DVT), weakness or spasticity depending on the level of spinal compression, and supraclavicular lymphadenopathy may also be detected. ${ }^{[23]}$ 


\section{Imaging methods}

Magnetic resonance imaging (MRI) is the best imaging method for assessing the prostate and adjacent tissue. T1-weighted (T1W1) magnetic resonance (MRI) is especially helpful for evaluating the prostate gland, seminal vesicles, and periprostatic fatty tissues (neurovascular fibers, perivesical tissues, and lymph nodes). In order to prevent artifacts of bleeding related to the biopsy, MRI should be conducted at least 4-6 weeks after biopsy. T2-weighted imaging (T2-WI) is better for viewing the internal zonal anatomy of the prostate. Prostate cancer typically exhibits decreased signal intensity in the peripheral zone in T2-WI. ${ }^{[8]}$

Technological advances in recent years resulting in the discovery of $3 \mathrm{~T}$ and multiparametric imaging has enabled higher resolution and improved staging accuracy. Dynamic contrast enhancement (DCE)-MRI can reliably distinguish the tumor from non-cancerous tissue. ${ }^{[38]}$ Another method, diffusion-weighted imaging (DWI)-MRI benefits

Table 2. Definitions for T, N, M

\begin{tabular}{|c|c|c|c|}
\hline \multicolumn{2}{|c|}{ Clinical T (cT) } & \multicolumn{2}{|c|}{ Pathological T (pT) } \\
\hline $\mathrm{T}$ & Primary tumor & $\mathrm{T}$ & Primary tumor \\
\hline TX & Primary tumor cannot be assessed & $\mathrm{T} 2$ & Organ confined \\
\hline T0 & No evidence of primary tumor & T3 & Extraprostatic extension \\
\hline $\mathrm{T} 1$ & Clinically inapparent tumor that is not palpable & T3a & $\begin{array}{l}\text { Extraprostatic extension (unilateral or bilateral) or } \\
\text { microscopic } \\
\text { invasion of bladder neck }\end{array}$ \\
\hline T1a & $\begin{array}{l}\text { Tumor incidental histologic finding in 5\% or less of tissue } \\
\text { resected }\end{array}$ & $\mathrm{T} 3 \mathrm{~b}$ & Tumor invades seminal vesicle(s) \\
\hline $\mathrm{T} 1 \mathrm{~b}$ & $\begin{array}{l}\text { Tumor incidental histologic finding in more than } 5 \% \text { of } \\
\text { tissue resected }\end{array}$ & $\mathrm{T} 4$ & $\begin{array}{l}\text { Tumor is fixed or invades adjacent structures other than } \\
\text { seminal vesicles such as external sphincter, rectum, bladder, } \\
\text { levator muscles, and/or pelvic wall. }\end{array}$ \\
\hline $\mathrm{T} 1 \mathrm{c}$ & $\begin{array}{l}\text { Tumor identified by needle biopsy found in one or both } \\
\text { sides, but not palpable }\end{array}$ & Note: & There is no pathological T1 classification \\
\hline $\mathrm{T} 2$ & Tumor is palpable and confined within prostate & Note: & $\begin{array}{l}\text { Positive surgical margin should be indicated by an } \mathrm{R} 1 \\
\text { descriptor, indicating residual microscopic disease. }\end{array}$ \\
\hline $\mathrm{T} 2 \mathrm{a}$ & Tumor involves one-half of one side or less & $\mathrm{N}$ & Regional lymph nodes \\
\hline $\mathrm{T} 2 \mathrm{~b}$ & $\begin{array}{l}\text { Tumor involves more than one-half of one side but not } \\
\text { both sides }\end{array}$ & NX & Regional lymph nodes cannot be assessed \\
\hline $\mathrm{T} 2 \mathrm{c}$ & Tumor involves both sides & No & No positive regional nodes \\
\hline T3 & $\begin{array}{l}\text { Extraprostatic tumor that is not fixed or does not invade } \\
\text { adjacent structures }\end{array}$ & N1 & Metastases in regional node(s) \\
\hline T3a & Extraprostatic extension (unilateral or bilateral) & M & Distant metastasis \\
\hline $\mathrm{T} 3 \mathrm{~b}$ & Tumor invades seminal vesicle(s) & M0 & No distant metastasis \\
\hline \multirow[t]{5}{*}{$\mathrm{T} 4$} & $\begin{array}{l}\text { Tumor is fixed or invades adjacent structures other than } \\
\text { seminal vesicles such as external sphincter, rectum, } \\
\text { bladder, levator muscles, and/or pelvic wall. }\end{array}$ & M1 & Distant metastasis \\
\hline & & M1a & Nonregional lymph node(s) \\
\hline & & M1b & Bone(s) \\
\hline & & M1c & Other site(s) with or without bone disease \\
\hline & & Note: & $\begin{array}{l}\text { When more than one site of metastasis is present the most } \\
\text { advanced category is used M1 is most advanced. }\end{array}$ \\
\hline
\end{tabular}


Table 3. American Joint Committee on Cancer (AJCC) $8^{\text {th }}$ edition Prognostic groups

\begin{tabular}{|c|c|c|c|c|c|}
\hline Groups & $\mathrm{T}$ & $\mathrm{N}$ & M & PSA (ng/mL) & Grade group \\
\hline \multirow[t]{3}{*}{ Stage I } & cT1a-c & NO & M0 & PSA $<10$ & 1 \\
\hline & cT2a & NO & M0 & PSA $<10$ & 1 \\
\hline & pT2 & NO & M0 & PSA $<10$ & 1 \\
\hline \multirow[t]{5}{*}{ Stage II } & cT1a-c & NO & M0 & $P S A \geq 10<20$ & 1 \\
\hline & cT2a & NO & M0 & $P S A \geq 10<20$ & 1 \\
\hline & pT2 & No & M0 & $P S A \geq 10<20$ & 1 \\
\hline & $\mathrm{cT} 2 \mathrm{~b}$ & NO & M0 & PSA $<20$ & 1 \\
\hline & cT2c & NO & M0 & PSA $<20$ & 1 \\
\hline Stage IIB & T1-2 & NO & M0 & PSA $<20$ & 2 \\
\hline \multirow[t]{2}{*}{ Stage IIC } & T1-2 & NO & M0 & PSA $<20$ & 3 \\
\hline & T1-2 & NO & M0 & PSA $<20$ & 4 \\
\hline Stage IIIA & T1-2 & NO & M0 & $\mathrm{PSA} \geq 20$ & $1-4$ \\
\hline Stage IIIB & T3-4 & NO & M0 & Any PSA & $1-4$ \\
\hline Stage IIIC & Any $\mathrm{T}$ & NO & M0 & Any PSA & 5 \\
\hline Stage IVA & Any $\mathrm{T}$ & N1 & M0 & Any PSA & Any \\
\hline Stage IVB & Any $\mathrm{T}$ & Any $N$ & M1 & Any PSA & Any \\
\hline
\end{tabular}

PSA: Prostate-specific antigen.

from tumor cell density, which restricts the movement of water molecules.

Magnetic resonance spectroscopy (MRS) may be used to evaluate the cellular metabolism of prostate cancer with benign intraglandular changes. In prostate cancer, loss of peak citrate as well as choline/creatine peak is observed. ${ }^{[39]}$

Distant metastasis can be determined with Galium 68-PSMA positron emission tomographycomputed tomography (PET-CT) and bone scintigraphy. This is recommended for newly diagnosed patients with high risk factors. ${ }^{[8]}$

\section{STAGING}

American Joint Committee on Cancer (AJCC) $8^{\text {th }}$ edition is currently used for cancer staging (Table 2-4). ${ }^{[40]}$

\section{TREATMENT OPTIONS}

Three distinct treatment modalities are available for newly diagnosed non-metastatic prostate cancer. The first is active surveillance, which is a regular follow-up method in lowrisk patients due to the fact that prostate cancer occurs at advanced ages and progresses

Table 4. D'amico risk classification

\begin{tabular}{lccc}
\hline & PSA $(\mathrm{ng} / \mathrm{mL})$ & Gleason sum & Clinical stage \\
\hline Low risk & $\leq 10$ & $\leq 6$ & $\leq \mathrm{T} 2 \mathrm{a}$ \\
Intermediate risk & $10-20$ & 7 & T2b \\
High risk & $\geq 20$ & $8-10$ & $\geq \mathrm{T} 2 \mathrm{c}$ \\
\hline PSA: Prostate-specific antigen. & &
\end{tabular}


slowly. The other treatment modality is radical prostatectomy and radiotherapy. In consideration to the patient's risk factors, androgen blockage treatment and chemotherapy may also be added.

D'Amico Risk Classification is the most commonly used method for classifying risk. Patients are divided into three risk groups: low, intermediate, and high. ${ }^{[4]]}$

\section{Active surveillance}

Since prostate cancer is seen in elderly men, studies have shown that a majority of these patients die from other comorbid causes. ${ }^{[42]}$ Therefore, active surveillance is an option in low-risk patients to avoid adverse effects of treatment. This is recommended in asymptomatic, low-risk patients with localized disease. Active surveillance is suitable for men with very low-risk prostate cancer and life expectancy $\geq 20$ y and for men with low risk prostate cancer and lifeexpectancy $\geq 10 y$. It involves careful follow-up and not initiating treatment as long as there is no disease progression or symptoms. Although there is currently no consensus, active surveillance is usually performed as periodic follow-up examinations (once every 3-6 months), PSA tests, and recurrent biopsy (once a year). The inevitable advantages of active surveillance are that two of every three patients do not require treatment and the avoidance of adverse effects due to unnecessary treatment. ${ }^{[43]}$ Its disadvantages are delayed treatment due to disease progression and the anxiety experienced by patients.

\section{Radical prostatectomy}

Radical prostatectomy (RP) is a suitable treatment method for patients with clinically localized prostate cancer that can be completely excised with surgery, who have an expected life span of 10 years or more, and without serious comorbid contraindications to the operation. ${ }^{[43]}$ Expanded pelvic lymph node dissection (PLND) is recommended. ${ }^{[43]}$ It provides a more complete staging and can also treat microscopic metastases.

The most common side effect is urinary incontinence. Risk of urinary incontinence can be reduced by preserving the urethral length beyond the apex of the prostate and not damaging the distal sphincter mechanism. Preservation of the bladder neck reduces incontinence risk.
Anastomotic stenoses increase the risk of long-term incontinence. Another side effect is erectile dysfunction, which is directly related to the patient's age when undergoing radical prostatectomy, preoperative erectile function, and the degree of preservation of the cavernous nerves.

The North American Prostate Cancer Intervention versus Observation Trial (PIVOT) evaluated the effectiveness of radical prostatectomy in close to 800 patients, however, its effect on survival compared to surveillance could not be established. Although not statistically significant, its contribution to life expectancy in patients under the age of 65 and intermediate/high-risk patients was observed. ${ }^{[44]}$

\section{Radiotherapy}

In the last decade, radiation techniques have been developed to provide better coverage of tumor volumes, with better preservation of neighboring normal structures. As a result of technological advances, radiotherapy (RT) provides a lower side effect profile, better sexual function, and lower rates of urinary incontinence compared to radical prostatectomy (RP), and is also a treatment method equivalent to radical prostatectomy in terms of treatment effectiveness.

Radiotherapy techniques used in prostate cancer include external beam radiation therapy (EBRT), proton treatment, and brachytherapy. EBRT techniques include intensity-modulated radiation therapy, hypofractionated radiotherapy, and image-guided stereotactic body radiation therapy (SBRT).

In prostate cancer patients, SBRT and intensitymodulated radiation therapy (IMRT) were found to have similar toxicity profiles, while proton therapy lowered urine toxicity but was related with increased intestinal toxicity. ${ }^{[45]}$

External beam radiation therapy is one of the main treatment options in clinically localized prostate cancer. According to the National Comprehensive Cancer Network (NCCN) consensus, modern EBRT and surgical trials showed similar progression-free survival in lowrisk patients. ${ }^{[43]}$

Proton beam radiation therapy implements the unique physical properties of high-energy 
protons produced from a cyclotron. Accelerated charged particles pass through tissue until they reach a depth determined by their energy and stop after reaching the targeted tissue. Use of more than one proton beam forms a very sharp and tight radiation dose distribution. This method is preferred especially when tumors are close to sensitive organs. ${ }^{[46]}$

Brachytherapy refers to the method of implanting a radioactive source directly to the prostate gland. While it is equivalent to EBRT in low-risk patients, in high-risk patients, it has low success rate on its own. However, it may be used supplementary to EBRT. ${ }^{[47]}$

\section{Which method is superior?}

The 10-year results of the Prostate Cancer and Treatment Test (ProtecT) conducted in the UK suggests a course of action in the management of localized prostate cancer. A total of 1,643 patients between ages 50-69 who were diagnosed with localized prostate cancer between 1999 and 2009 were included in the study. Patients of all risk groups were randomized in groups. 545 men underwent active surveillance, 553 surgery, and 545 radiotherapy. The active surveillance group had more progression than the surgery and RT group, however, there was no significant difference in number of deaths. In summary, in a 10-year median, prostate cancerspecific mortality rate was low, independent from the treatment received, and there was no significant difference between the modes of treatment. ${ }^{[48]}$

Kupelian et al. ${ }^{[4]}$ compared radical prostatectomy to radiotherapy and included 1,682 patients in their study conducted in Cleveland Clinic. Radiotherapy was applied to 628 patients and 1,054 patients underwent surgery. Results of the study demonstrated that eight-year biochemical disease-free survival (bDFS) was $72 \%$ in the radical prostatectomy group and $70 \%$ in the radiotherapy group; there was no statistically significant difference between the two groups. Age, race, and treatment modality were not found to have an effect on treatment success. When radiotherapy treatment was grouped according to dosage of $<72 \mathrm{~Gy}$ and $>72 \mathrm{~Gy}$, dosage under 72 Gy was related to treatment failure. ${ }^{[49]}$
Surveillance, epidemiology, and end results (SEER) conducted a 10-year retrospective study on 60,290 men and found that prostate cancer-related deaths were $1.3 \%$ in the radical prostatectomy group, $0.5 \%$ in the brachytherapy group, and $3.7 \%$ in the active surveillance group. ${ }^{[50]}$

In summary, although the effect of active surveillance on survival is uncertain, we do know that it increases progression. It may be considered equivalent to the other treatment modalities of RT and surgery. Some studies have indicated that the reason RP is found superior to RT is because only patients with good general conditions are candidates for the surgery, and that those with comorbid disease undergo RT rather than surgery.

\section{Androgen deprivation therapy}

In patients with intermediate to high-risk prostate cancer, androgen deprivation therapy (ADT) is added to radiotherapy to provide medical castration. ${ }^{[43]}$ Patients with intermediate risk are recommended 4-6 months of ADT and high-risk patients are recommended $1.5-3$ years ADT. In intermediate-risk patients, adding 3-6 months ADT has been shown to increase bDFS by $10-25 \%$ and disease-related survival by 3-8\%.[11] One study on high-risk patients found that adding long-term ADT to radiotherapy increased five-year diseasefree survival from 40 to $74 \%$ and five-year general survival from 62 to $78 \%$. ${ }^{[58]}$

Eight randomized controlled trials on 4,141 men with high-risk prostate cancer found that ADT use was not related with increased risk of cardiovascular mortality. Androgen deprivation therapy treatment has been shown to be associated with both prostate cancer-related and all-cause mortality reduction. ${ }^{[53]}$

Androgen deprivation treatments frequently used in the clinic include: the luteinizing hormone-releasing hormone (LHRH) agonists goserelin, histrelin, leuprolide, and triptorelin; the anti-androgens nilutamide, flutamide, and bicalutamide; and the LHRH antagonist degarelix.

In androgen-sensitive non-metastatic disease, ADT treatment is preferred. If the disease is metastatic, or has low metastatic burden, radiotherapy is preferred. If metastatic burden 
is increased, Docetaxel (6 cycles of $75 \mathrm{mg} / \mathrm{m}^{2}$ ), abiraterone + prednisone, apalutamide, and enzalutamide are preferred. ${ }^{[43]}$

In non-metastatic disease that is unresponsive to medical castration, serum testosterone level is tried to be kept at $<50 \mathrm{ng} / \mathrm{dL}$. If PSA doubling time is over 10 months, treatment is continued. If doubling time less than 10 months, apalutamide, darolutamide, or enzalutamide is added. ${ }^{[43]}$

\section{Metastatic disease}

In metastatic disease, genetic mutations and family history are questioned. If serum testosterone level is $<50 \mathrm{ng} / \mathrm{dL}$, ADT is continued. In the presence of bone metastases, denosumab or zoledronic acid are initiated. Sipuleucel-T may be administered for immunotherapy. Pain treatment and supportive care are applied. In cases of the pathological subtypes small cell carcinoma or neuroendocrine prostate cancer, cisplatin/etoposide, carboplatin/etoposide, or docetaxel/carboplatin is administered. Radium-223 treatment can be applied only when there are no extensive metastases of the internal organs but only widespread bone metastases.

\section{Radium-223 treatment}

Radium-223 is an alpha-emitting radiopharmaceutical that has been shown to increase survival in men with symptomatic bone metastases, castration-resistant prostate cancer (CRPC), without visceral metastasis. Radium-223 has not been shown to prolong survival in men with visceral metastasis or bulky nodal disease (>3 to $4 \mathrm{~cm}$ ) alone..$^{[43,54]}$

Radium-223 causes double-strand breaks in DNA and subsequent cell death. Radium-223 is a calcimimetic agent that specifically targets bone lesions. It is administered intravenously once a month for six months. Grade 3-4 hematological toxicity (2\% neutropenia, 3\% thrombocytopenia, 6\% anemia) may rarely occur. Simultaneous use of denosumab or zoledronic acid does not affect the beneficial effects of radium-223 on survival. ${ }^{[54]}$

\section{Recurrence after radical prostatectomy}

Post-RP PSA persistence/recurrence is interpreted as PSA not falling to undetectable levels (PSA persistence) or undetectable PSA after RP which increases to $>0.2 \mathrm{mg} / \mathrm{dL}$. Pelvic/ abdomen MRI, bone scintigraphy or PSMA PET$\mathrm{CT}$ should be requested. If there is no metastasis, radiotherapy and $\mathrm{ADT}$ should be applied. If there is metastasis, chemotherapy can be added to ADT. ${ }^{[43]}$

\section{Recurrence after radiotherapy}

According to the Phoenix criteria, confirmed PSA $>2$ after radiotherapy is considered treatment failure. Prostate-specific antigen doubling time, bone imaging, prostate MRI, and TRUS biopsy are performed for risk classification. In the case of biopsy positivity and no metastasis, radical prostatectomy + pelvic lymph node dissection, cryotherapy, or brachytherapy is preferred. If the biopsy is negative, surveillance or ADT is preferred.

\section{Declaration of conflicting interests}

The authors declared no conflicts of interest with respect to the authorship and/or publication of this article.

\section{Funding}

The authors received no financial support for the research and/or authorship of this article.

\section{REFERENCES}

1. Garnick MB. Prostate cancer: screening, diagnosis, and management. Ann Intern Med 1993;118:804-18.

2. Parkin DM, Whelan SL, Ferlay J, Teppo L, Thomas $\mathrm{DB}$, editors. Cancerincidence in fivecontinents, Vol VII. Lyon: IARC SciPubl; 1997.

3. Statistics Sweden Cancer incidence in Sweden, 1999, Statistics Sweden, Stockholm; 2001.

4. Siegel RL, Miller KD, Jemal A. Cancer statistics, 2019. CA Cancer J Clin 2019;69:7-34.

5. PSA: prostate-specific antigen, persisting scientific ambiguities. Harv Mens Health Watch 2009;13:1-6.

6. Potosky AL, Miller BA, Albertsen PC, Kramer BS. The role of increasing detection in the rising incidence of prostate cancer. JAMA 1995;273:548-52.

7. Gunderson LL, Tepper JE. Clinical radiation oncology. Elsevier Health Sciences; 2015.

8. Lichtenstein P, Holm NV, Verkasalo PK, Iliadou A, Kaprio J, Koskenvuo M, et al. Environmental and heritable factors in the causation of cancer--analyses of cohorts of twins from Sweden, Denmark, and Finland. N Engl J Med 2000;343:78-85.

9. Carter BS, Bova GS, Beaty TH, Steinberg GD, Childs B, Isaacs WB, et al. Hereditary prostate cancer: epidemiologic and clinical features. J Urol 1993;150:797-802. 
10. Carpten J, Nupponen N, Isaacs S, Sood R, Robbins $\mathrm{C}, \mathrm{Xu} \mathrm{J}$, et al. Germline mutations in the ribonuclease $\mathrm{L}$ gene in families showing linkage with HPC1. Nat Genet 2002;30:181-4.

11. Giovannucci E, Stampfer MJ, Krithivas K, Brown M, Dahl D, Brufsky A, et al. The CAG repeat within the androgen receptor gene and its relationship to prostate cancer. Proc Natl Acad Sci U S A 1997;94:3320-3.

12. Chang B, Zheng SL, Isaacs SD, Wiley KE, Carpten JD, Hawkins GA, et al. Linkage and association of CYP17 gene in hereditary and sporadic prostate cancer. Int J Cancer 2001;95:354-9.

13. Nam RK, Toi A, Vesprini D, Ho M, Chu W, Harvie $\mathrm{S}$, et al. V89L polymorphism of type-2, 5-alpha reductase enzyme gene predicts prostate cancer presence and progression. Urology 2001;57:199204.

14. Xu J, Zheng SL, Carpten JD, Nupponen NN, Robbins CM, Mestre J, et al. Evaluation of linkage and association of HPC2/ELAC2 in patients with familial or sporadic prostate cancer. Am J Hum Genet 2001;68:901-11.

15. Armstrong B, Doll R. Environmental factors and cancer incidence and mortality in different countries, with special reference to dietary practices. Int $\mathrm{J}$ Cancer 1975;15:617-31.

16. Chan JM, Stampfer MJ, Ma J, Gann PH, Gaziano JM, Giovannucci EL. Dairy products, calcium, and prostate cancer risk in the Physicians' Health Study. Am J Clin Nutr 2001;74:549-54.

17. Luo J, Zha S, Gage WR, Dunn TA, Hicks JL, Bennett $\mathrm{CJ}$, et al. Alpha-methylacyl-CoA racemase: a new molecular marker for prostate cancer. Cancer Res 2002;62:2220-6.

18. Strom SS, Yamamura Y, Duphorne CM, Spitz MR, Babaian RJ, Pillow PC, et al. Phytoestrogen intake and prostate cancer: a case-control study using a new database. Nutr Cancer 1999;33:20-5.

19. Lippman SM, Klein EA, Goodman PJ, Lucia MS, Thompson IM, Ford LG, et al. Effect of selenium and vitamin $E$ on risk of prostate cancer and other cancers: the Selenium and Vitamin E Cancer Prevention Trial (SELECT). JAMA 2009;301:39-51.

20. Gaziano JM, Sesso HD, Christen WG, Bubes V, Smith JP, MacFadyen $J$, et al. Multivitamins in the prevention of cancer in men: the Physicians' Health Study II randomized controlled trial. JAMA 2012;308:1871-80.

21. Giovannucci E, Rimm EB, Liu Y, Stampfer MJ, Willett WC. A prospective study of tomato products, lycopene, and prostate cancer risk. J Natl Cancer Inst 2002;94:391-8.

22. Huggins C, Hodges CV. Studies on prostatic cancer. I. The effect of castration, of estrogen and of androgen injection on serum phosphatases in metastatic carcinoma of the prostate. 1941. J Urol 2002;167:948-51.
23. Beyzadeoglu M, Ozyigit G, Ebruli C. Basic Radiation Oncology. Berlin Heidelberg: Springer-Verlag; 2010.

24. Salagierski M, Schalken JA. Molecular diagnosis of prostate cancer: PCA3 and TMPRSS2:ERG gene fusion. J Urol 2012;187:795-801.

25. Schröder FH, Hugosson J, Roobol MJ, Tammela TL, Ciatto S, Nelen V, et al. Screening and prostatecancer mortality in a randomized European study. N Engl J Med 2009;360:1320-8.

26. Carter HB, Albertsen PC, Barry MJ, Etzioni R, Freedland SJ, Greene KL, et al. Early detection of prostate cancer: AUA Guideline. J Urol 2013;190:419-26.

27. Fine SW, Reuter VE. Anatomy of the prostate revisited: implications for prostate biopsy and zonal origins of prostate cancer. Histopathology 2012;60:142-52.

28. American Cancer Society: Cancer Facts and Figures 2008. Atlanta, Ga: American Cancer Society; 2008.

29. Bonkhoff $\mathrm{H}$, Stein $\mathrm{U}$, Remberger K. The proliferative function of basal cells in the normal and hyperplastic human prostate. Prostate 1994;24:114-8.

30. Algaba F, Epstein JI, Aldape HC, Farrow GM, LopezBeltran A, Maksem J, et al. Assessment of prostate carcinoma in core needle biopsy--definition of minimal criteria for the diagnosis of cancer in biopsy material. Cancer 1996;78:376-81.

31. Bostwick DG, Brawer MK. Prostatic intra-epithelial neoplasia and early invasion in prostate cancer. Cancer 1987;59:788-94.

32. Keith JD, Akhavan A, Bastacky SI, Cari C, Wang $\mathrm{Y}$, Nelson JB. Extent of high-grade prostatic intraepithelial neoplasia (HGPIN) on initial biopsy is significantly associated with prostate cancer on repeat biopsy. J Urol 2006; 175:173-7.

33. Humphrey PA. Diagnosis of adenocarcinoma in prostate needle biopsy tissue. J Clin Pathol 2007;60:35-42.

34. Gleason D. Histologic grading of prostatic carcinoma. In: Bostwick D, editor. Pathology of the prostate. New York: Churchill Livingstone; 1990. p. 83.

35. Grayhack JT, Grayhack JJ. Clinical dilemmas and problems in assessing prostatic metastasis to bone: the scientific challenge. Adv Exp Med Biol 1992;324:1-5.

36. Chodak GW, Vogelzang NJ, Caplan RJ, Soloway M, Smith JA. Independent prognostic factors in patients with metastatic (stage D2) prostate cancer. The Zoladex Study Group. JAMA 1991;265:618-21.

37. Chybowski FM, Keller JJ, Bergstralh EJ, Oesterling $\mathrm{JE}$. Predicting radionuclide bone scan findings in patients with newly diagnosed, untreated prostate cancer: prostate specific antigen is superior to all other clinical parameters. J Urol 1991;145:313-8.

38. Padhani AR, Gapinski CJ, Macvicar DA, Parker GJ, Suckling J, Revell PB, et al. Dynamic contrast enhanced MRI of prostate cancer: correlation with morphology and tumour stage, histological grade and PSA. Clin Radiol 2000;55:99-109. 
39. Zakian KL, Hricak H, Ishill N, Reuter VE, Eberhardt $\mathrm{S}$, Moskowitz CS, et al. An exploratory study of endorectal magnetic resonance imaging and spectroscopy of the prostate as preoperative predictive biomarkers of biochemical relapse after radical prostatectomy. J Urol 2010;184:2320-7.

40. Buyyounouski MK, Choyke PL, Kattan MW. Prostate. In: Amin MB, editors. AJCC Cancer Staging Manual. 8th ed. New York: Springer; 2017. p. 715.

41. Singh J, Trabulsi EJ, Gomella LG. Is there an optimal management for localized prostate cancer? Clin Interv Aging 2010;5:187-97.

42. Ries LA, Melbert D, Krapcho M, editors. SEER Cancer Statistics Review, 1975-2005 Based on 2007 Nov SEER data submission, postedtothe SEER website. Bethesda, MD: National Cancer Institute; 2008.

43. Mohler JL, Antonarakis ES, Armstrong AJ, D'Amico AV, Davis BJ, Dorff $\mathrm{T}$, et al. Prostate Cancer, Version 2.2019, NCCN Clinical Practice Guidelines in Oncology. J Natl Compr Canc Netw 2019;17:479-505.

44. Wilt TJ, Jones KM, Barry MJ, Andriole GL, Culkin D, Wheeler T, et al. Follow-up of Prostatectomy versus Observation for Early Prostate Cancer. N Engl J Med 2017;377:132-42.

45. Pan HY, Jiang J, Hoffman KE, Tang C, Choi SL, Nguyen QN, et al. Comparative Toxicities and Cost of Intensity-Modulated Radiotherapy, Proton Radiation, and Stereotactic Body Radiotherapy Among Younger Men With Prostate Cancer. J Clin Oncol 2018;36:1823-30.

46. Gay HA, Michalski JM. Radiation Therapy for Prostate Cancer. Mo Med 2018;115:146-50.

47. Koukourakis G, Kelekis N, Armonis V, Kouloulias $\mathrm{V}$. Brachytherapy for prostate cancer: a systematic review. Adv Urol 2009:327945.
48. Hamdy FC, Donovan JL, Lane JA, Mason M, Metcalfe C, Holding P, et al. 10-Year Outcomes after Monitoring, Surgery, or Radiotherapy for Localized Prostate Cancer. N Engl J Med 2016;375:1415-24.

49. Kupelian PA, Elshaikh M, Reddy CA, Zippe C, Klein EA. Comparison of the efficacy of local therapies for localized prostate cancer in the prostate-specific antigen era: a large single-institution experience with radical prostatectomy and external-beam radiotherapy. $\mathrm{J}$ Clin Oncol 2002;20:3376-85.

50. Tward JD, Lee CM, Pappas LM, Szabo A, Gaffney DK, Shrieve DC. Survival of men with clinically localized prostate cancer treated with prostatectomy, brachytherapy, or no definitive treatment: impact of age at diagnosis. Cancer 2006;107:2392-400.

51. Pilepich MV, Winter K, John MJ, Mesic JB, Sause W, Rubin $\mathrm{P}$, et al. Phase III radiation therapy oncology group (RTOG) trial 86-10 of androgen deprivation adjuvant to definitive radiotherapy in locally advanced carcinoma of the prostate. Int $\mathrm{J}$ Radiat Oncol Biol Phys 2001;50:1243-52.

52. Bolla M, Collette L, Blank L, Warde P, Dubois $\mathrm{JB}$, Mirimanoff $\mathrm{RO}$, et al. Long-term results with immediate androgen suppression and external irradiation in patients with locally advanced prostate cancer (an EORTC study): a phase III randomised trial. Lancet 2002;360:103-6.

53. Nguyen PL, Je Y, Schutz FA, Hoffman KE, Hu JC, Parekh A, Beckman JA, et al. Association of androgen deprivation therapy with cardiovascular death in patients with prostate cancer: a meta-analysis of randomized trials. JAMA 2011;306:2359-66.

54. Deshayes E, Roumiguie M, Thibault C, Beuzeboc P, Cachin F, Hennequin C, et al. Radium 223 dichloride for prostate cancer treatment. Drug Des Devel Ther 2017;11:2643-51. 